\title{
A combined experimental and theoretical study of gas sorption on nanoporous silver triazolato metal-organic frameworks
}

\author{
Guang Yang ${ }^{\mathrm{a}, \mathrm{b}}$, Juan A. Santana ${ }^{\mathrm{a}, \mathrm{c}}$, Milton E. Rivera-Ramos ${ }^{\mathrm{d}}$, Omar García-Ricard ${ }^{\mathrm{d}}$, \\ Jose J. Saavedra-Arias ${ }^{\mathrm{a}, 1}$, Yasuyuki Ishikawa ${ }^{\mathrm{a}}$, Arturo J. Hernández-Maldonado ${ }^{\mathrm{d}}$, Raphael G. Raptis ${ }^{\mathrm{a}, *}$ \\ a Department of Chemistry and the Institute for Functional Nanomaterials, University of Puerto Rico, P.O. Box 70377, San Juan, PR 00936-8377, USA \\ ${ }^{\mathrm{b}}$ College of Chemistry and Molecular Engineering, Zhengzhou University, Zhengzhou 450001, China \\ ' Space Sciences Laboratory, University of California, Berkeley, CA 94720, USA \\ ${ }^{\mathrm{d}}$ Department of Chemical Engineering and the Institute for Functional Nanomaterials, University of Puerto Rico-Mayagüez, P.O. Box 9000, Mayagüez, PR 00681-9000, USA
}

\section{A R T I C L E I N F O}

\section{Article history:}

Received 26 March 2013

Received in revised form 27 August 2013

Accepted 2 September 2013

Available online 11 September 2013

\section{Keywords:}

Flexible MOF

$\mathrm{CO}_{2}$ sorption

Silver pyrazolate

$\mathrm{X}$-ray structure

DFT calculations

\begin{abstract}
A B S T R A C T
A new silver-triazolate metal-organic framework (MOF), $\left\{\mathrm{Ag}_{3}\left[\mathrm{Ag}_{5}\left(\mu_{3}-3,5-{ }^{\mathrm{t}} \mathrm{Bu}_{2} \mathrm{tz}\right)_{6}\right]\left(\mathrm{BF}_{4}\right)_{2}\right\}_{n}(\mathbf{2})$, has been prepared and structurally characterized. The $\mathrm{CO}_{2}$ sorption properties of this new MOF and previously reported isostructural analog $\left\{\mathrm{Ag}_{3}\left[\mathrm{Ag}_{5}\left(\mu_{3}-3,5-\mathrm{Ph}_{2} \mathrm{tz}\right)_{6}\right]\left(\mathrm{NO}_{3}\right)_{2}\right\}_{n}$ (1), were determined experimentally and probed theoretically by a density functional (DF) method. The structures of $\mathbf{1}$ and $\mathbf{2}$ are based on flexible $\mathrm{Ag}_{5} \mathrm{tz}_{6}$-structural building units (SBUs), which allow the expansion/contraction of the structure, depending on either the steric requirements of the pendant groups $-{ }^{t} \mathrm{Bu}$, or $\mathrm{Ph}$ - of the SBUs, or the pressure of the gaseous sorbate. Both silver-triazolate MOFs sorb $\mathrm{CO}_{2}$ preferentially to $\mathrm{N}_{2}, \mathrm{O}_{2}, \mathrm{CH}_{4}$ and $\mathrm{H}_{2}$. DF calculations show $\mathrm{CO}_{2}$ to be bound by van der Waals forces to the organic moieties of the porous framework. This work shows that van der Waals interactions of $\mathrm{CO}_{2}$ and the aromatic and aliphatic hydrocarbons of silver-triazolate MOFs are sufficient to achieve preferential sorption of $\mathrm{CO}_{2}$.
\end{abstract}

(c) 2013 Elsevier Inc. All rights reserved.

\section{Introduction}

The field of metal-organic frameworks (MOFs) has been expanding, because of the potential utility of MOFs in gas storage and separation [1-5], catalysis [6-9], drug delivery [10], and biomedical imaging [11]. Several reviews on the synthesis, characterization and applications of MOFs are available [12-20].

A large effort has been directed towards the synthesis of materials with ever-increasing pore volume and surface area [21-25], as well as with pore surfaces that interact preferentially with a desired sorbate [26-29]. However, while tight sorbent-sorbate binding on one hand facilitates sorption, it impedes desorption on the other, requiring wider temperature or pressure swings to recycle the sorbent. It follows that fine-tuning of the sorption/desorption properties is required for the successful development of optimum and durable sorbents. Consequently, in-depth understanding of the nature and thermodynamics of sorbent-sorbate interactions is essential for further progress of the field.

\footnotetext{
* Corresponding author. Address: Department of Chemistry and Biochemistry, Florida International University, Miami, FL 33199, USA. Tel.: +1 3053487529. E-mail address: rraptis@fiu.edu (R.G. Raptis).

1 Present address: Department of Physics, Universidad Nacional, Heredia 40101, Costa Rica.
}

Towards that goal, molecular dynamics and Monte Carlo methods have been successfully employed for the simulation of gas sorption on a variety of porous materials [30,14]. Calculations based on density functional theory (DFT) have elucidated the nature of the interaction of small molecules with the surface of porous materials. For instance, in a recent combined experimental and computational study [31], dispersion corrected periodic DF calculations [32] were carried out to investigate the $\mathrm{CO}_{2}$ interactions with the $\left[\mathrm{Zn}_{2} \text { (3-amino-1,2,4-triazole) }{ }_{2} \text { (oxalate) }\right]_{n}$-MOF. Efforts to develop new force fields that describe accurately the interaction between $\mathrm{CO}_{2}$ and the sorbent along a complete adsorption isotherm are continuing [33].

The capture and recycling of $\mathrm{CO}_{2}$ is a contemporary problem, related to global warming by greenhouse gases, but also to the remediation of breathing air in confined environments, such as spacecraft during extended space missions, whose mitigation via the use of MOF-based devices has been proposed [34-36]. The separation of $\mathrm{CO}_{2}$ from $\mathrm{CH}_{4}$ and $\mathrm{H}_{2}$ are also processes of major industrial importance [37-42]. Carbon dioxide sequestration is efficiently achieved by amine scrubbers (chemisorption), whose regeneration, however, is energetically costly [43]. The need for the development of lower cost $\mathrm{CO}_{2}$ capture technology has lead to the proposed application of MOFs to that end [44]. Along these lines, amine-functionalized MOFs have been studied and shown to also have high $\mathrm{CO}_{2}$ binding energy - approximately $10 \mathrm{kcal} / \mathrm{mol}$ for 
one of them [45-47]. A $\gamma$-cyclodextrin-based MOF binds $\mathrm{CO}_{2}$ by reversible formation of carbonates with the hydroxy groups of the oligosaccharide frame [48]. Examples of weaker, but still selective $\mathrm{CO}_{2}$ binding by weak $\mathrm{H}$-bonds to hydroxy groups, or by dispersion forces to exposed metal-ion sites, have been reported [47,49-51]. In a OH-functionalized MOF, the energy of end-on bound $\mathrm{CO}_{2}$ to a hydroxy group was determined to be $5.4 \mathrm{kcal} /$ mol [38]. While high binding energy is desirable for trace $\mathrm{CO}_{2}$ removal at low pressure, minimization of that energy is required for a recyclable sorbent system.

As part of our work towards the preparation of readily recyclable $\mathrm{CO}_{2}$-sorbent MOFs, we present here the results of experimental and computational gas sorption studies on two related nanoporous MOFs based on silver triazolate units with the general formula $\left\{\left[\mathrm{Ag}_{8}\left(\mu_{3}-3,5-\mathrm{R}_{2}-\mathrm{tz}\right)_{6}\right]^{2+}\right\}_{n}-\mathrm{tz}=1,2,4$-triazolate anion $-\mathrm{R}=\mathrm{Ph}(\mathbf{1})$ and ${ }^{t} \mathrm{Bu}(\mathbf{2})$. These two MOFs differ by the dangling R-groups that line the pore surfaces. The synthesis and X-ray structure of $\mathbf{2}$ are also reported; those of $\mathbf{1}$ have already been reported [52].

\section{Experimental}

Reagents were purchased from Sigma Aldrich and used as received. Adsorbate gases used were $\mathrm{CO}_{2}$ (Ultra High Purity Grade, Praxair), $\mathrm{N}_{2}$ (Ultra High Purity Grade, Linde), $\mathrm{O}_{2}$ (Ultra High Purity Grade, Linde), $\mathrm{CH}_{4}$ (Ultra High Purity Grade, Praxair) and He (High Purity Grade, Linde). Solvents were distilled prior to use. The preparation of 3,5-di-tert-butyl-1,2,4-triazole (3,5- $\left.{ }^{\mathrm{t}} \mathrm{Bu}_{2} \mathrm{tzH}\right)$ was carried out by a literature procedure [53]. The thermogravimetric analysis (TGA) was performed with a NETZSCH STA409PC system in air at a heating rate of $10^{\circ} \mathrm{C} / \mathrm{min}$. The powder X-ray diffraction pattern of 2 was recorded with a Rigaku D/MAX-3B X-ray diffactometer.

$\left\{\left[\mathrm{Ag}_{8}\left(\mu_{3}-3,5-{ }^{\mathrm{t}} \mathrm{Bu}_{2}-\mathrm{tz}\right)_{6}\right]\left[\mathrm{BF}_{4}\right]_{2}\right\}_{n}$, 2. An aqueous solution $(1 \mathrm{~mL})$ of $\mathrm{AgBF}_{4}(0.1 \mathrm{mmol}, 19 \mathrm{mg})$ was mixed with an acetonitrile solution $(1 \mathrm{~mL})$ of $3,5-{ }^{\mathrm{t}} \mathrm{Bu}_{2} \mathrm{tzH}(0.1 \mathrm{mmol}, 18 \mathrm{mg})$. The resulting solution was allowed to evaporate slowly to afford colorless crystals in $40 \%$ yield within $1-2$ weeks. Anal. Calcd (\%) for $\mathrm{C}_{60} \mathrm{H}_{108} \mathrm{~N}_{18} \mathrm{Ag}_{8} \mathrm{~B}_{2} \mathrm{~F}_{8}$ : C, 34.0; H, 5.1; N, 11.9; F, 7.2. Found: C, 34.1; H, 5.1; N, 11.7; F, 7.9\%. IR ( $\mathrm{KBr}$ pellet, $\mathrm{cm}^{-1}$ ): $2963 \mathrm{~s}, 1462 \mathrm{~m}, 1415 \mathrm{w}, 1365 \mathrm{w}, 1218 \mathrm{~m}$, $1083 \mathrm{~s}, 486 \mathrm{w}$.

\subsection{X-ray crystallography}

Diffraction data were collected with a Siemens SMART $1 \mathrm{~K} \mathrm{CCD}$ diffractometer using graphite monochromated Mo-Ka ( $\lambda=0.71073 \AA$ ) radiation at $298 \mathrm{~K}$ using the program SMART-NT and were processed by SAINT-NT [54,55]. An empirical absorption correction was applied by the program SADABS. The space group, $P 6_{3} 22$, is not uniquely defined by the systematically absent reflections, therefore, solution of the structure was attempted in the alternative hexagonal space groups, $P 6_{3} / \mathrm{mmm}, P 6_{3} \mathrm{~mm}$ and $P 6_{3}$. Of those, the first two gave chemically meaningless solutions. A meaningful solution was obtained in $P 6_{3}$, but its refinement was not better than the one in the higher-symmetry $P 6_{3} 22$, which was preferred. The structure was solved by direct methods and refined by full-matrix least-squares methods on $F^{2}$ [56-58]. All non-hydrogen atoms were refined anisotropically. H-atoms were placed in calculated positions with their thermal parameters riding on those of their C-atoms. The crystallographic disorder of the freelyrotating ${ }^{\mathrm{t}} \mathrm{Bu}$-groups could not be modeled satisfactorily. However, as their presence at the 3- and 5-positions of the tz-ligands is unequivocal, they were included in the refinement using restraints. The $\mathrm{BF}_{4}^{-}$anions were not located in difference maps, as their electron density was smeared along with that of interstitial solvent molecules. The final structure refinement was performed after the data were treated by the SQUEEZE routine of the PLATON suite of programs [59] to remove unaccounted for residual electron density due to disordered solvent molecules and anions occupying the void spaces. For 2: $\mathrm{C}_{60} \mathrm{H}_{108} \mathrm{Ag}_{8} \mathrm{~B}_{2} \mathrm{~F}_{8} \mathrm{~N}_{18}, M=2118.22$, hexagonal, $P 6_{3} 22$ (No. 182), $a=b=21.420(3), c=14.320$ (3) $\AA, \quad V=5690.0(16) \AA^{3}$, $Z=2, \rho_{\text {calcd. }}=1.236 \mathrm{~g} \mathrm{~cm}^{-3}, \mu=1.392 \mathrm{~mm}^{-1}, 40501$ reflections collected, 3801 independent $\left(R_{\text {int }}=0.1225\right), 86$ parameters, 36 restraints, $R_{1}=0.0865$ for 2361 observed reflections with $I>2 \sigma(I)$ (0.1194 for all data), $w R_{2}=0.2341, S=0.992, \Delta \rho_{\max }=1.002 \mathrm{e}^{-3}$.

\subsection{Adsorption equilibrium isotherms}

Equilibrium adsorption isotherms in the $1 \mathrm{~atm}$ pressure range were gathered using a Micromeritics ASAP 2020 static volumetric adsorption system outfitted with molecular drag pumps. Helium was used as a backfill gas after the pre-treatment stage and removed using ultra-high vacuum prior to adsorption tests. All samples (ca. $150 \mathrm{mg}$ each) were loaded into glass holders fitted with isolation valves and then pre-treated in vacuum at $403 \mathrm{~K}$. An evacuation rate of $50 \mathrm{mmHg} / \mathrm{s}$ was used and the ultimate vacuum was held at $20 \mu \mathrm{mHg} / \mathrm{s}$ for $12 \mathrm{~h}$. Once the vacuum set point was achieved, the sample was heated at a $10 \mathrm{~K} / \mathrm{min}$ rate. The heating phase lasted approximately $3 \mathrm{~h}$. For carbon dioxide, equilibrium tests were performed at temperatures ranging from 298 to $353 \mathrm{~K}$. Tests for $\mathrm{N}_{2}, \mathrm{CH}_{4}$ and $\mathrm{O}_{2}$ were performed only at $298 \mathrm{~K}$. During the experiments, the temperature was kept constant by means of a heating blanket. Desorption tests were performed immediately after reaching the $1 \mathrm{~atm}$ pressure target.

High-pressure adsorption isotherms were gathered using a Micromeritics ASAP 2050 volumetric instrument capable of reaching a maximum of $10 \mathrm{~atm}$. The procedure for sample activation, including backfill, was identical to the one mentioned above. The adsorption and desorption analyses were performed in the $10 \mathrm{~atm}$ range at 273 and $298 \mathrm{~K}$, respectively.

\section{3. $\mathrm{CO}_{2}$ isosteric heat of adsorption $\left(\mathrm{H}_{\text {ads }}\right)$}

The Clausius-Clapeyron equation (Eq. (1)) and pure $\mathrm{CO}_{2}$ equilibrium adsorption data at different temperatures and constant surface loading were used to estimate the isosteric heats of adsorption.

$$
\left.\left(\frac{d \ln P}{d(1 / T)}\right)\right|_{q=\text { const }}=\frac{\Delta H_{a d s}}{R}
$$

In this equation $R$ is the gas constant, $P$ is the equilibrium pressure at a particular coverage $q$ and $T$ is the absolute temperature.

\subsection{DFT calculations}

All geometry optimizations were carried out using the $\mathrm{DMol}^{3}$ program of Accelrys Inc [60,61]. During geometry optimization, the experimental geometry of the silver-triazolate MOFs was used and kept fixed, while the gaseous sorbates were allowed full relaxation. Perdew-Burke-Ernzerhof (PBE) exchange and correlation functionals were employed $[62,63]$. The Kohn-Sham orbitals were expanded in double numerical plus polarization (DNP) basis set. The fractional occupation number technique [60,61] was employed with an energy width of $0.1 \mathrm{eV}$. Gamma k-point was used for all calculations.

To determine the binding energy of gaseous sorbates in the silver-triazolate MOFs, a semi-empirical dispersion correction was added to the DFT energy [64,32]. Energy calculations were carried out using the QUANTUMESPRESSO package [65] and the geometries optimized with $\mathrm{DMol}^{3}$. The ionic cores were represented by ultrasoft pseudopotentials [66] and the electronic one-particle 
wave functions were expanded in a plane-wave basis set. PBE exchange and correlation functionals were employed [62,63]. Wave function and charge-density cut-offs were 30 and 300 Ry, respectively. A self-consistency convergence criterion of at least $1 \times 10^{-4}$ Ry and gamma k-point were used for all calculations.

\section{Results and discussion}

$\left\{\mathrm{Ag}_{3}\left[\mathrm{Ag}_{5}\left(\mu_{3}-3,5-{ }^{\mathrm{t}} \mathrm{Bu}_{2} \mathrm{tz}\right)_{6}\right]\left(\mathrm{BF}_{4}\right)_{2}\right\}_{n}, 2$, is isostructural with the previously reported 3,5- $\mathrm{Ph}_{2} \mathrm{tz}$ analog, 1 [52]. Both compounds crystallize in the hexagonal $P 6_{3} 22$ space group with one-sixth formula unit per asymmetric unit. Their structures consist of 6-connected $\mathrm{Ag}_{5} \mathrm{tz}_{6}$ structural building units (SBUs) linked by six linear 2-coordinate Ag-center linkers, resulting in approximately trigonal-prismatic $\mathrm{Ag}_{6 / 2}\left[\mathrm{Ag}_{5} \mathrm{tz}_{6}\right]$-motifs (Fig. 1), with their axes parallel to the crystallographic $c$-direction and coinciding with the crystallographic threefold rotation axes. The 3-dimensional $\left\{\mathrm{Ag}_{6 / 2}\left[\mathrm{Ag}_{5} \mathrm{tz}_{6}\right]^{2+}\right\}_{n}$-lattices of $\left(4^{9} .6^{6}\right)$-acs topology form channels along the $6_{3}$-axes (Fig. 2 ), which are lined by the $3,5-R_{2}$-substituent groups of the triazolates. Comparison of the structure of $3,5-{ }^{\mathrm{t}} \mathrm{Bu}_{2} \mathrm{tz}^{-}$complex 2 with that of $3,5-\mathrm{Ph}_{2} \mathrm{tz}^{-}$complex 1 reveals that, while the corresponding $\mathrm{Ag}-\mathrm{N}$ bonds are similar in length, the trigonal-prismatic units of $\mathbf{2}$ are elongated in the c-direction compared to those of $1(\sim 7.28 \AA$ vs. $\sim 6.01 \AA)$, as a consequence of the larger steric requirements of ${ }^{\mathrm{t}} \mathrm{Bu}-\mathrm{vs}$. Ph-groups. As a result of this elongation, the $\mathrm{Ag}_{6 / 2}\left[\mathrm{Ag}_{5} \mathrm{tZ}_{6}\right]$-motifs of 2 are contracted along the $a$ - and $b$-directions (Scheme 1 ) in a "breathing" motion, increasing the diameter of the hexagonal channels (Fig. 2). Thus, the more than double porosity of $2(\sim 44 \% \mathrm{v} / \mathrm{v})$ with respect to that of $\mathbf{1}(\sim 21 \% \mathrm{v} / \mathrm{v})$ is controlled by the triazole peripheral substitution.

The expandable nature of the $\mathrm{Ag}_{5} \mathrm{tz}_{6}$-core of $\mathbf{1}$ and $\mathbf{2}$ reflects the flexibility of coordination geometry of Ag-centers. While the $\mathrm{BF}_{4}^{-}$ anions were not located in the difference maps of the X-ray structure of $\mathbf{2}$, their presence is required for charge balance and is consistent with the elemental analysis of $\mathbf{2}$.

Azolates are convenient supporting ligands for the synthesis of a wide variety of MOFs [67]. Disubstituted tridentate triazolates, 3,5- $\mathrm{R}_{2}-\mathrm{tz}^{-}$, in particular, form MOFs in which the R-groups define the pore surfaces, allowing the tuning of its sorption properties, as well as control of its pore volume. This is exemplified by two fluorinated silver-triazolato MOFs, FMOF-1 and FMOF-2 - related

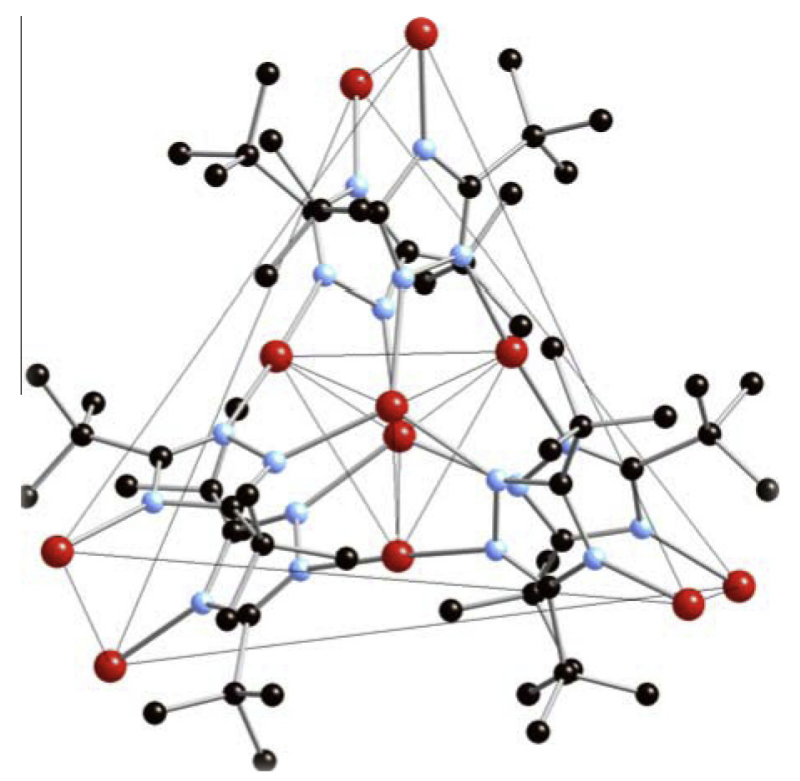

Fig. 1. Ball-and-stick diagram of the $\mathrm{Ag}_{6 / 2}\left[\mathrm{Ag}_{5} \mathrm{tz}_{6}\right]$ trigonal-prismatic motif of 2 .

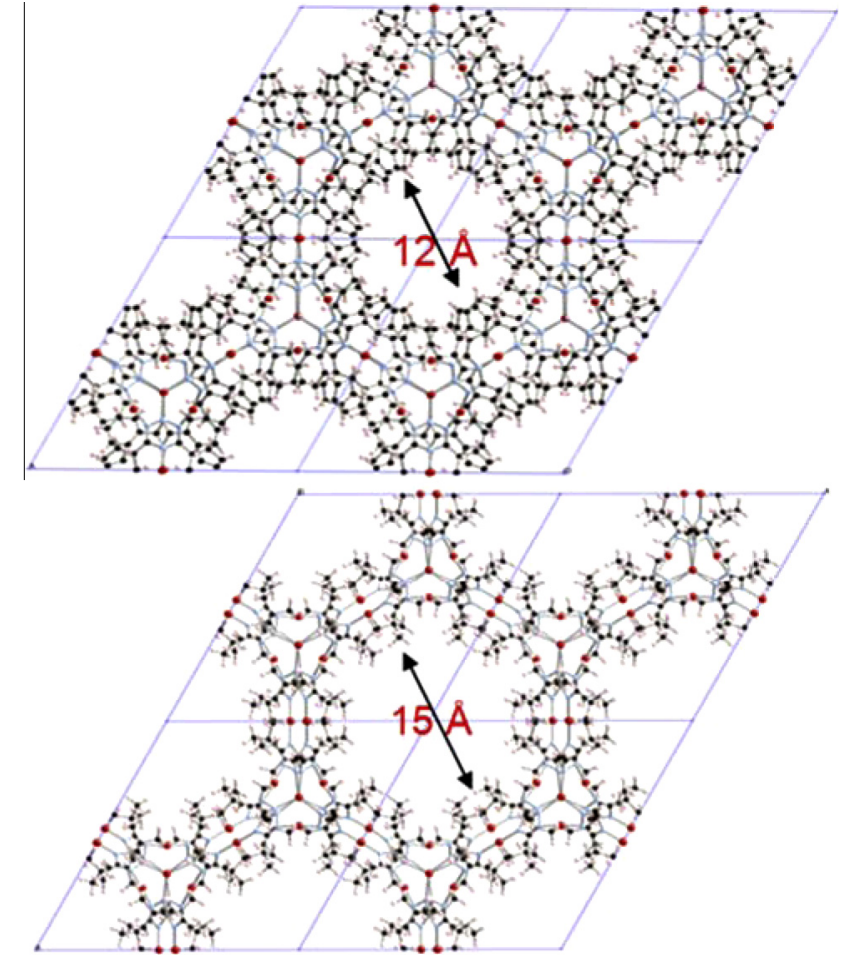

Fig. 2. The hexagonal channels of $\mathbf{1}$ (upper) and $\mathbf{2}$ (lower) viewed parallel to the crystallographic $\mathrm{c}$-axes. Color code: $\mathrm{Ag}$, red; $\mathrm{N}$, blue, $\mathrm{H}$, pink. The arrows indicate approximate atom-to-atom distances across the hexagonal pores.
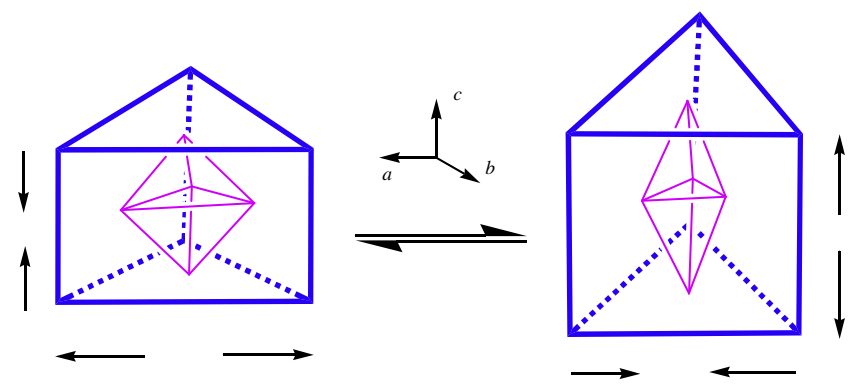

Scheme 1.

materials to 1 and 2 with 3,5- $\left(\mathrm{CF}_{3}\right)_{2}-\mathrm{tz}^{-}$- which are rendered hydrophobic by their perfluoromethyl groups and have been proposed as a suitable sorbents for the clean-up of oil spills [68]. The availability here of $\mathbf{1}$ and $\mathbf{2}$, differing only in the nature of their pendant R-groups and the minor structural modifications caused by the different steric requirements of those groups, allows the evaluation of their importance to the $\mathrm{CO}_{2}$ sorption properties of the bulk porous materials.

The pore volume of $\mathbf{2}$ is occupied by solvent molecules, which are easily removed by drying in a desiccator under reduced pressure. A TGA (Appendix A) of pre-dried 2 shows no weight loss up to $500 \mathrm{~K}$. However, single crystals withdrawn directly from the mother liquor and used for the X-ray crystallographic study showed smeared electron density attributed to disordered solvent molecules occupying the lattice voids.

The powder X-ray diffraction pattern of $\mathbf{2}$ was compared to a simulated one based on the single crystal X-ray structure (Appendix A) to confirm the structural identity of the bulk sample and single crystal. Low partial pressure (up to $1 \mathrm{~atm}$ ) pure component 
equilibrium adsorption isotherms are gathered in Fig. 3. Both $\mathbf{1}$ and 2 display selectivity toward $\mathrm{CO}_{2}$ over $\mathrm{CH}_{4}, \mathrm{O}_{2}$ and $\mathrm{N}_{2}$, which increases with partial pressure. Since the linear shape of the isotherms correlates well with weak adsorbate-absorbent interactions, the selectivity displayed by the adsorbents toward $\mathrm{CO}_{2}$ is attributed to the quadrupolar nature of $\mathrm{CO}_{2}$. The kinetic diameters of these four gases are all significantly smaller than the pore diameters of $\mathbf{1}$ and $\mathbf{2}$, so, there is no size discrimination control in play. However, $\mathrm{CO}_{2}$ has the largest polarizability among the gases tested, resulting in larger surface potentials. In fact, the interaction is at the physisorption level, as evidenced by complete reversibility during vacuum desorption tests (data not shown here) and by the isosteric heat of adsorption profiles (see Fig. 4). In the case of $\mathbf{1}$, the stepped heat of adsorption profile is consistent with some level of surface heterogeneity, such as one that might have been generated by lattice expansion and exposure of previously inaccessible sorption sites. The fact that the crystallographically determined porosities of $\mathbf{1}$ and $\mathbf{2}$ differ significantly - 21\% and $44 \%$, respectively - yet these two MOFs have essentially identical $\mathrm{CO}_{2}$ sorption capacities (Fig. 3), is also consistent with the flexible nature of these materials. Under pressure, 1 can expand reaching the dimensions of already "stretched" 2.

Tests performed for high-pressure $\mathrm{CO}_{2}$ adsorption resulted in the isotherms shown in Fig. 5. It is remarkable that even at a pressure up to $10 \mathrm{~atm}$ the isotherm shape remained linear. At this point, however, there are approximately $15 \mathrm{CO}_{2}$ molecules adsorbed per unit cell in $\mathbf{1}$ (or, $7-8 \mathrm{CO}_{2}$ molecules per $\left[\mathrm{Ag}_{8} \mathrm{tz}_{6}\right]^{2+}$-unit) and this number matches well with the amount required for saturation of the pore assuming a liquid-like $\mathrm{CO}_{2}$ adsorbed phase. The latter was calculated using the crystallographic unit cell porosity of 1 before expansion (21\%) and the density of $\mathrm{CO}_{2}$ at liquid state.
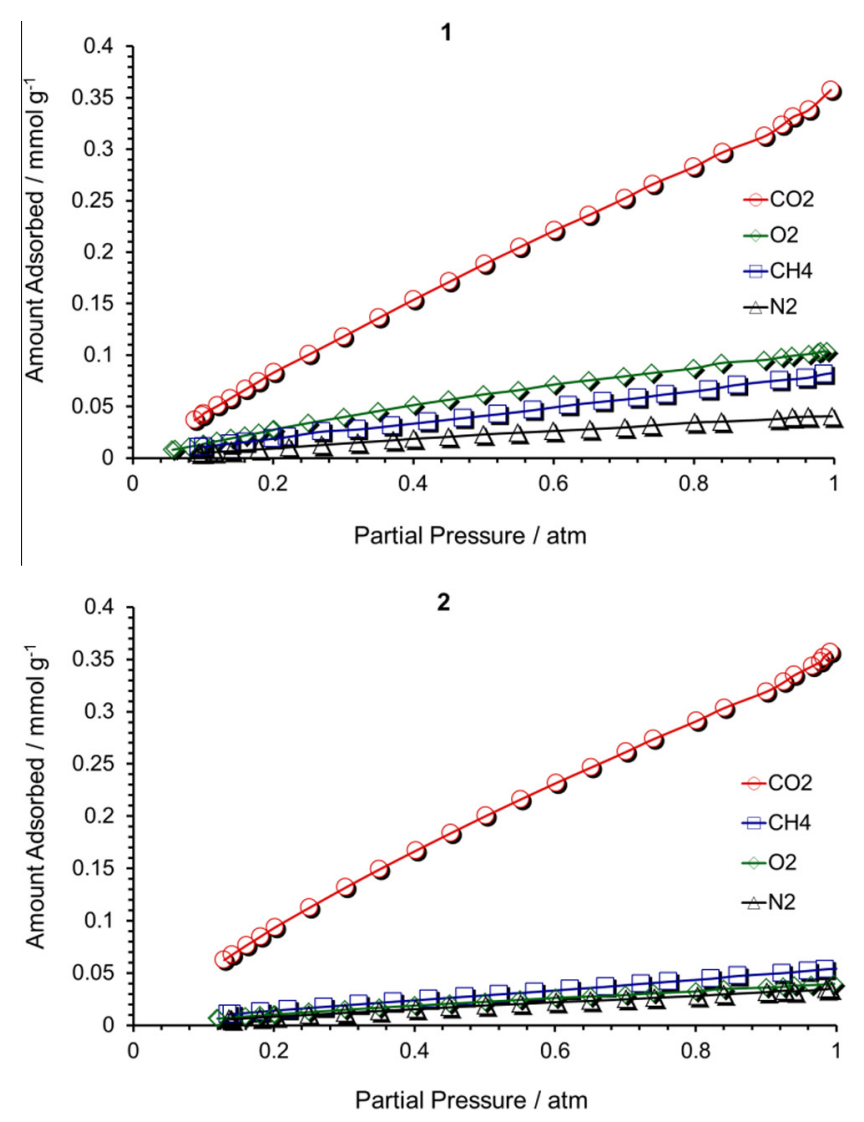

Fig. 3. Pure component adsorption isotherms for $\mathrm{CO}_{2}, \mathrm{CH}_{4}, \mathrm{O}_{2}$ and $\mathrm{N}_{2}$ on $\mathbf{1}$ (upper) and 2 (lower) at $298 \mathrm{~K}$.

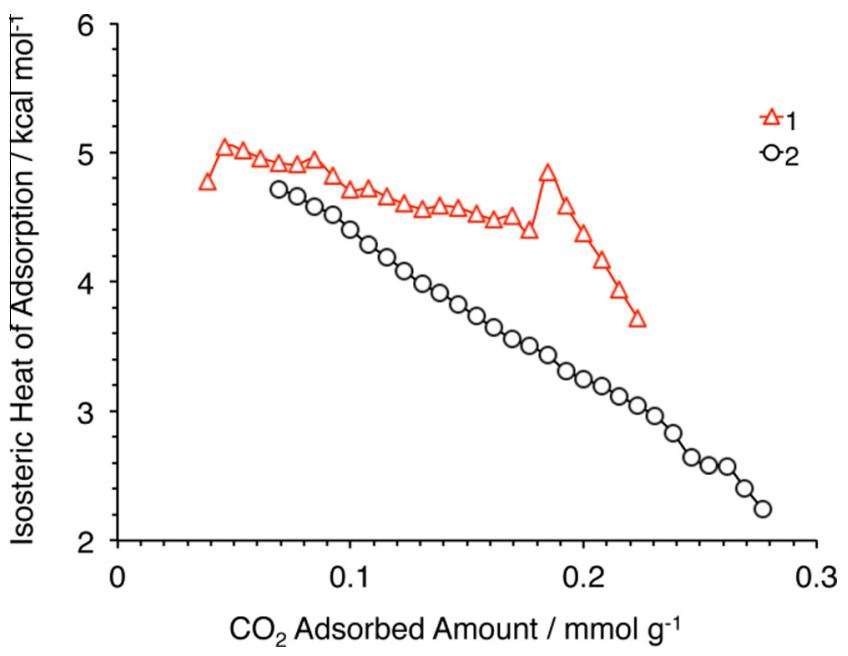

Fig. 4. Experimental isosteric heats of $\mathrm{CO}_{2}$ adsoprtion in $\mathbf{1}$ and $\mathbf{2}$.

Given these results, it appears that pore saturation for $\mathbf{1}$ should be in the vicinity of the 10 atm pressure mark, but it was not possible to verify this due to experimental limitations. However, the linear appearance of the sorption curve throughout the $0-10 \mathrm{~atm}$ range suggests otherwise - e.g., the saturation point lies further away - suggesting a lattice deformation and expansion of the pore volume of $\mathbf{1}$. In the case of $\mathbf{2}$, the amount of $\mathrm{CO}_{2}$ adsorbed at ca. $10 \mathrm{~atm}$ corresponds to ca. 3 molecules per unit cell, well below the saturation value ( 21 molecules per unit cell) estimated from the crystallographic unit porosity (44\%). Contrary to the observations made for $\mathbf{1}$, it appears that $\mathbf{2}$ does not experience a structural expansion in the $10 \mathrm{~atm}$ range.

Desorption tests performed after reaching a partial pressure of $10 \mathrm{~atm}$, however, contrasted with the results observed during the low-pressure adsorption tests. Fig. 5 shows a considerable hysteresis upon desorption, with approximately $25 \%$ and $12 \%$ of $\mathrm{CO}_{2}$ remaining sorbed on $\mathbf{1}$ and $\mathbf{2}$, respectively, upon evacuation at ambient temperature. This may be due to encapsulation of adsorbate molecules into faults or small framework cavities. In the case of $\mathbf{1}$, the $\mathrm{CO}_{2}$ remaining trapped within the void may be due to framework expansion. Significant lattice expansion has also been reported for the analogous silver triazolato FMOF-1 [68], consistent with the observations of SBU flexibility made here. According to a Modified Dubinin-Astakhov (MDA) fit analysis [69,70], at the

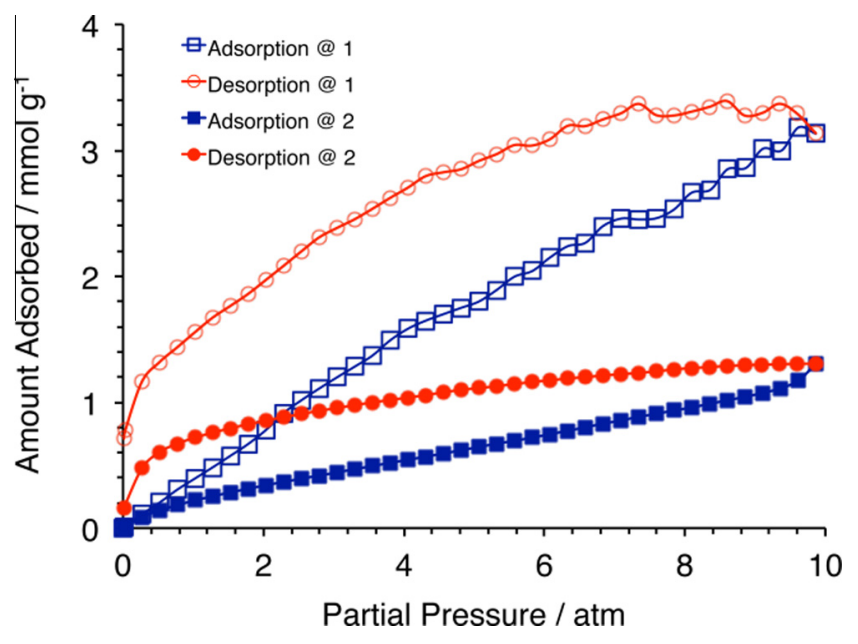

Fig. 5. $\mathrm{CO}_{2}$ sorption/desorption isotherms for $\mathbf{1}$ and $\mathbf{2}$ at $298 \mathrm{~K}$. 
expanded stage, the pore volume of 1 is about $0.18 \mathrm{~cm}^{3} / \mathrm{g}$, corresponding to $29 \%$ porosity (Appendix A). This is $38 \%$ larger than the porosity estimated from crystallographic data for $\mathbf{1}$ at its relaxed state and sound evidence of a significant lattice expansion upon adsorption of $\mathrm{CO}_{2}$.

The $\mathrm{CO}_{2}$ sorption sites and its isosteric heats of adsorption on $\mathbf{1}$ and $\mathbf{2}$ were probed by DFT calculations, whose results are summarized in Table 1 and Fig. 6. Three different types of exposed $\mathrm{Ag}$-centers were examined first as possible $\mathrm{CO}_{2}$ sorption sites and were found to be sterically hindered by the surrounding phenyl or tert-butyl groups and counter ions (Appendix A). Consequently, other possible MOF sites were examined. The sorption energies reached maxima at sites where the $\mathrm{CO}_{2}$ molecule is at 3.0-3.4 from four $\mathrm{H}$-atoms of the phenyl or tert-butyl groups. Within a distance of $4 \AA$, there are 8 (for $\mathbf{1}$ ) and 10 (for $\mathbf{2}$ ) $\mathrm{H}-\mathrm{CO}_{2}$ contacts. Comparison of these distances with the Bondi radii of oxygen and hydrogen atoms ( $1.52 \AA$ and $1.20 \AA$, respectively) suggests weak van der Waals (vdW) interactions [71]. A total of 24 equivalent such sites exist per unit cell for the capture of $\mathrm{CO}_{2}$ which, however, cannot be occupied simultaneously for steric reasons - the unit cell pore volume, determined from the crystal structure of $\mathbf{1}$ (at $1 \mathrm{~atm}$ ), cannot accommodate 24 molecules of solid or liquid phase $\mathrm{CO}_{2}$, assuming a rigid structure. An expandable structure, however, should be able to accommodate more gas molecules. The sorption data correspond to only 1.5 sorbed $\mathrm{CO}_{2}$ molecules per unit cell of 1 at $1 \mathrm{~atm}$ and $15 \mathrm{CO}_{2}$ molecules at $10 \mathrm{~atm}$ (Fig. 3). This is consistent with the linear increase of sorbed $\mathrm{CO}_{2}$ with pressure and the fact that the $\mathrm{CO}_{2}$ saturation point of $\mathbf{1}$ was not reached at $10 \mathrm{~atm}$. The calculated sorption enthalpies for consecutive $\mathrm{CO}_{2}$ molecule introduction to the pores indicate a steady minor decrease up to four $\mathrm{CO}_{2}$ molecules for $\mathbf{1}$ and up to six $\mathrm{CO}_{2}$ molecules for $\mathbf{2}$, up to which point there are no $\mathrm{CO}_{2}-\mathrm{CO}_{2}$ interactions. Further $\mathrm{CO}_{2}$ addition causes a steady increase in sorption energy, attributed to new $\mathrm{CO}_{2}-\mathrm{CO}_{2}$ interactions (Appendix A).

Because of the good agreement between experimental and calculated ISA, the computational work was extended to include the sorption of $\mathrm{H}_{2}$ for which there are no experimental data. The calculated isosteric heats for $\mathrm{H}_{2}$ adsorption are similar, or lower, than those of $\mathrm{N}_{2}, \mathrm{O}_{2}$ and $\mathrm{CH}_{4}$, indicating that $\mathrm{CO}_{2}$ should be preferentially sorbed on $\mathbf{1}$ or $\mathbf{2}$ from $\mathrm{CO}_{2} / \mathrm{H}_{2}$ mixtures. The calculated vdW interaction energy, $4.57 \mathrm{kcal} / \mathrm{mol}$, between $\mathrm{CO}_{2}$ and the $\mathrm{Ph}$ group in 1 is nearly double those of $\mathrm{CH}_{4}, \mathrm{~N}_{2}, \mathrm{O}_{2}$ with the $\mathrm{Ph}$ group, rendering highly selective $\mathrm{CO}_{2}$ uptake feasible. This trend is also seen in $\mathbf{2}$, where the vdW interactions are between the small molecules and the ${ }^{t} \mathrm{Bu}$ group. The preferential sorption of $\mathrm{CO}_{2}$ can be rationalized considering the polarizability of $\mathrm{CO}_{2}, \mathrm{CH}_{4}, \mathrm{~N}_{2}, \mathrm{O}_{2}$ and $\mathrm{H}_{2}$. vdW interactions, e.g., dispersion interaction, arise from the polarization in the sorbent and sorbate systems. The average electric dipole polarizability $\left(10^{-24} \mathrm{~cm}^{3}\right)$ of $\mathrm{CO}_{2}, \mathrm{CH}_{4}, \mathrm{~N}_{2}, \mathrm{O}_{2}$ and $\mathrm{H}_{2}$ is $2.91,2.59,1.74,1.58$ and 0.80 , respectively [72]. The vdW interaction energy of these sorbates with $\mathbf{1}$ and $\mathbf{2}$ (Table 1) in

Table 1

Adsorption capacities and calculated isosteric heats of adsorption (ISA) of gases on $\mathbf{1}$ and 2.

\begin{tabular}{|c|c|c|c|c|}
\hline & 1 & 1 & 2 & 2 \\
\hline & $\begin{array}{l}\text { Adsorption } \\
\text { Capacity } \\
(\mathrm{mmol} / \mathrm{g})\end{array}$ & $\begin{array}{l}\text { Calculated } \\
\Delta H_{\text {ads }} \text { (kcal/ } \\
\text { mol) }\end{array}$ & $\begin{array}{l}\text { Adsorption } \\
\text { Capacity } \\
(\mathrm{mmol} / \mathrm{g})\end{array}$ & $\begin{array}{l}\text { Calculated } \\
\Delta H_{\mathrm{ads}} \text { (kcal/ } \\
\text { mol) }\end{array}$ \\
\hline $\mathrm{CO}_{2}$ & $0.36\left(3.13^{\mathrm{a}}\right)$ & 4.57 & $0.36\left(1.31^{\mathrm{a}}\right)$ & 3.59 \\
\hline $\mathrm{CH}_{4}$ & 0.08 & 2.90 & 0.05 & 2.34 \\
\hline $\mathrm{N}_{2}$ & 0.04 & 2.33 & 0.03 & 1.55 \\
\hline $\mathrm{O}_{2}$ & 0.10 & 2.11 & 0.04 & 1.75 \\
\hline $\mathrm{H}_{2}$ & - & 0.75 & - & 1.08 \\
\hline
\end{tabular}

a Experimental values at $10 \mathrm{~atm}$.

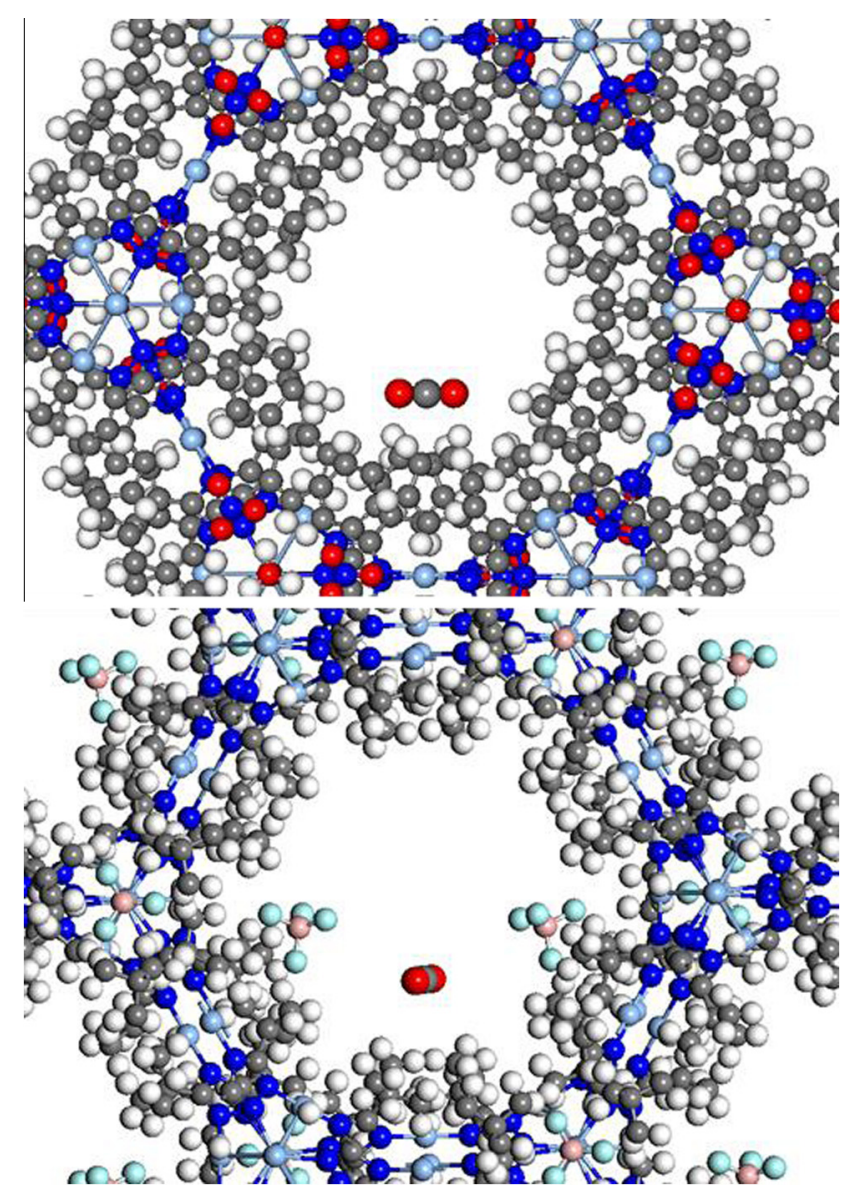

Fig. 6. $\mathrm{CO}_{2}$ position in $\mathbf{1}$ (upper) and $\mathbf{2}$ (lower) from DFT geometrical optimizations

general correlates with the polarizability of the sorbates. $\mathrm{CO}_{2}$ has a larger polarizability than the other gases and consequently higher vdW interaction energy.

From the sorption data for 1 in the $0-1$ atm range, selectivities estimated by the IAST model for $\mathrm{CO}_{2} / \mathrm{O}_{2}, \mathrm{CO}_{2} / \mathrm{CH}_{4}$ and $\mathrm{CO}_{2} / \mathrm{N}_{2}$ are $\sim 3.5,5.0$ and 10.5 , respectively. The corresponding selectivities for 2 are $\sim 9.0,9.0$ and 14.0 (Appendix A) [73,74].

\section{Conclusions}

In the present study, we performed experimental and computational gas sorption studies on two nanoporous silver triazolate based MOFs; $\left\{\left[\mathrm{Ag}_{8}\left(\mu_{3}-3,5-\mathrm{R}_{2}-\mathrm{tz}\right)_{6}\right]^{2+}\right\}_{n}-\mathrm{tz}=1,2,4$-triazolate anion $-\mathrm{R}=\mathrm{Ph}(\mathbf{1})$ and ${ }^{\mathrm{t}} \mathrm{Bu}(\mathbf{2})$. The two studied MOFs differ only in the phenyl vs. tert-butyl substituents, which line the surfaces of the hexagonal pores. However, the different steric requirements of the two groups cause small deformation of the soft coordination spheres of the silver cations, resulting in significantly different pore dimensions in $\mathbf{1}$ and $\mathbf{2}$. Yet, the ambient temperature gas sorption capacities of the two MOFs are within experimental error identical in the $0-1 \mathrm{~atm}$ range. The $\mathrm{CO}_{2}$ sorption capacities of 1 and 2 are much lower than the record-high $\sim 54 \mathrm{mmol} / \mathrm{g}$ (at 50 bar) reported for the MOF-210 [75]. On the other hand, 1 and 2 still show selective $\mathrm{CO}_{2}$ sorption over $\mathrm{N}_{2}, \mathrm{O}_{2}, \mathrm{CH}_{4}$ and $\mathrm{H}_{2}$, while their low $\mathrm{CO}_{2}$ binding energy should allow easy recycling of the sorbents.

Flexible MOFs, which expand as they admit a guest species under pressure or low temperature and contract with an hysteresis on desorption, similarly to $\mathbf{1}$, have been reported by others, but are not a common occurrence [76-79]. The breathing-in and -out 
behavior of a flexible silver-triazolato fremawork has been also observed previously in the related to 1 and 2 FMOF-1 [80]. In the latter case, it has been shown that its lattice expands in a two-step manner upon $\mathrm{N}_{2}$ sorption (at low temperature), the expansion being evident by the changes in its crystallographic dimensions contraction of the $a-, b-$, and elongation of the $c$-axis of its tetragonal unit cell. The same contraction and elongation is seen here when the hexagonal unit cells of $\mathbf{1}(a=b=21.60 \AA, c=12.20 \AA)$ and $2(a=b=21.42 \AA, c=14.32 \AA)$ are compared. However, in contrast to FMOF-1, 1 shows only one adsorption step. The already expanded lattice of 2 does not show a stepped $\mathrm{CO}_{2}$ adsorption process.

Since $\mathbf{1}$ and $\mathbf{2}$ have sterically hindered metal sites, while they do not contain any of the functional groups known to enhance $\mathrm{CO}_{2}$ binding (e.g., hydroxyl, amine or carboxylic groups), their binding sites were probed by computational methods. These studies revealed weak van der Waals binding at sites defined by $\mathrm{H}$-atoms of phenyl and tert-butyl groups. Structural evidence of weak binding to the $\pi$-density of phenyl groups has been presented recently in a calcium sulfonylbenzoate MOF [81]. However, in a separate work it has also been shown that $\mathrm{CO}_{2}$ binds preferentially to aliphatic rather than aromatic $\mathrm{C}-\mathrm{C}$ bonds when both types are available in a MOF [82]. Similar selective $\mathrm{CO}_{2}$ over $\mathrm{N}_{2}$ sorption properties as those of $\mathbf{1}$ and $\mathbf{2}$ have been reported for all-organic sorbents, such as peptides $[83,84]$ and covalent organic frameworks (COFs) [85]. Of course, much higher selectivities have been reported for ammonium- or amine-containing MOFs [86-88].

\section{Acknowledgements}

This work has been supported by the National Aeronautics and Space Administration (Grants NNX09AV05A and NNX08BA48A), the National Science Foundation (HRD-0833112) and the Institute for Functional Nanomaterials-UPR. YG acknowledges a Grant from the National Science Foundation of China (\#21071126).

\section{Appendix A. Supplementary data}

Supplementary data associated with this article (pore volume estimation by the MDA model, details of DFT calculations, selectivity estimation based on the IAST model, TGA and PXRD 15 pattern of 2) can be found, in the online version, at http://dx.doi.org/ 10.1016/j.micromeso.2013.09.006. Crystallographic information for 2 can be obtained free of charge from the Cambridge Crystallographic Data Centre (CCDC number 900770).

\section{References}

[1] E.D. Bloch, W.L. Queen, R. Krishna, J.M. Zadrozny, C.M. Brown, J.R. Long, Science 335 (2012) 1606-1610

[2] T.-H. Bae, J.S. Lee, W. Qiu, W.J. Koros, C.W. Jones, S. Nair, Angew. Chem. Int. Ed. 49 (2010) 9863-9866.

[3] S. Ma, H.-C. Zhou, Chem. Commun. 46 (2010) 44-53.

[4] J.-R. Li, R.J. Kuppler, H.-C. Zhou, Chem. Soc. Rev. 38 (2009) 1477-1504.

[5] R.E. Morris, P.S. Wheatley, Angew. Chem. Int. Ed. 47 (2008) 4966-4981.

[6] C. Wang, Z. Xie, J. Am. Chem. Soc. 133 (2011) 13445-13454.

[7] A. Corma, H. García, F.X. Llabrés I Xamena, Chem. Rev. 110 (2010) 4606-4655.

[8] L. Ma, C. Abney, W. Lin, Chem. Soc. Rev. 38 (2009) 1248-1256.

[9] L.L. Welbes, A.S. Borovik, Acc. Chem. Res. 38 (2005) 765-774.

[10] P. Horcajada, C. Serre, G. Maurin, N.A. Ramsahye, F. Balas, M. Vallet-Regí, M. Sebban, F. Taulelle, G. Férey, J. Am. Chem. Soc. 130 (2008) 6774-6780.

[11] J. Della Rocca, W. Lin, Eur. J. Inorg. Chem. (2010) 3725-3734.

[12] S.M. Cohen, Chem. Rev. 112 (2012) 970-1000.

[13] K.K. Tanabe, S.M. Cohen, Chem. Soc. Rev. 40 (2011) 498-519.

[14] J. Jiang, R. Babarao, Z. Hu, Chem. Soc. Rev. 40 (2011) 3599-3612.

[15] O.K. Farha, J.T. Hupp, Acc. Chem. Res. 43 (2010) 1166-1175.

[16] D.J. Tranchemontagne, J.L. Mendoza-Cortés, M. O’Keeffe, O.M. Yaghi, Chem. Soc. Rev. 38 (2009) 1257-1283.

[17] G. Férey, Dalton Trans. (2009) 4400-4415.

[18] G. Férey, Chem. Soc. Rev. 37 (37) (2008) 191-214.

[19] J.L.C. Roswell, O.M. Yaghi, Microporous Mesoporous Mater. 73 (2004) 3-14.
[20] S. Kitagawa, R. Kitaura, S. Noro, Angew. Chem. Int. Ed. 43 (2004) 2334-2375.

[21] O.K. Farha, I. Eryazici, N.C. Jeong, B.G. Hauser, C.E. Wilmer, A.A. Sarjeant, R.Q. Snurr, S.T. Nguyen, A.Ö. Yazaydin, J.T. Hupp, J. Am. Chem. Soc. 134 (2012) 15016-15021.

[22] H. Furukawa, N. Ko, Y.B. Go, N. Aratani, S.B. Choi, E. Choi, A.O. Yazaydin, R.Q. Snurr, M. O'Keeffe, J. Kim, O.M. Yaghi, Science 329 (2010) 424-428.

[23] O.K. Farha, A.O. Yazaydin, I. Eryazici, C.D. Malliakas, B.G. Hauser, M.G. Kanatzidis, S.T. Nguyen, R.Q. Snurr, J.T. Hupp, Nat. Chem. 2 (2010) 944-948.

[24] G. Ferey, C. Mellot-Draznieks, C. Serre, F. Millange, Acc. Chem. Res. 38 (2005) 217-225.

[25] B.L. Chen, M. Eddaoudi, S.T. Hyde, M. O'Keeffe, O.M. Yaghi, Science 291 (2001) 1021-1023.

[26] K. Oisaki, Q. Li, H. Furukawa, A.U. Czaja, O.M. Yaghi, J. Am. Chem. Soc. 132 (2010) 9262-9264.

[27] H. Den, C.J. Doonan, H. Furukawa, R.B. Ferreira, J. Towne, C.B. Knobler, B. Wang, O.M. Yaghi, Science 327 (2010) 846-850.

[28] S. Hasegawa, S. Horike, R. Matsuda, S. Furukawa, K. Mochizuki, Y. Kinoshita, S. Kitagawa, J. Am. Chem. Soc. 129 (2007) 2607-2614.

[29] H. Furukawa, J. Kim, K.E. Plass, O.M. Yaghi, J. Am. Chem. Soc. 128 (2006) 83988399.

[30] W. Zhuang, D. Yuan, D. Liu, C. Zhong, J.-R. Li, H.C. Zhou, Chem. Mater. 24 (2012) $18-25$.

[31] R. Vaidhyanathan, S.S. Iremonger, G.K.H. Shimizu, P.G. Boyd, S. Alavi, T.K. Woo, Science 330 (2010) 650-653.

[32] S. Grimme, J. Comput. Chem. 27 (2006) 1787-1799.

[33] A.L. Dzubak, L.-C. Lin, J. Kim, J.A. Swisher, R. Poloni, S.N. Maximoff, B. Smit, L. Gagliardi, Nat. Chem. 4 (2012) 810-816.

[34] C. Lastoskie, Science 330 (2010) 595-596.

[35] D.W. Keith, Science 325 (2009) 1654-1655.

[36] D.M. D’Alessandro, B. Smit, J.R. Long, Angew. Chem. Int. Ed. 49 (2010) 60586082.

[37] G. Férey, C. Serre, T. Devic, G. Maurin, H. Jobic, P.L. Llewellyn, G. De Weireld, A. Vimont, M. Daturi, J.-S. Chang, Chem. Soc. Rev. 40 (2011) 550-562.

[38] Z. Chen, S. Xiang, H.D. Arman, P. Li, D. Zhao, B. Chen, Eur. J. Inorg. Chem. (2011) 2227-2231.

[39] J. Roswell, O.M. Yaghi, J. Am. Chem. Soc. 128 (2006) 1304-1315.

[40] M.P. Suh, H.J. Park, T.K. Prasad, D.-W. Lim, Chem. Rev. 112 (2012) 782-835.

[41] Z.R. Herm, J.A. Swisher, B. Smit, R. Krishna, J.R. Long, J. Am. Chem. Soc. 133 (2011) 5664-5667.

[42] Y.-S. Bae, R.Q. Snurr, Angew. Chem. Int. Ed. 50 (2011) 11596.

[43] G.T. Rochelle, Science 325 (2009) 1652-1654.

[44] K. Sumida, D.R. Rogow, J.A. Mason, T.M. McDonald, E.D. Bloch, Z.R. Herm, T.-H. Bae, J.R. Long, Chem. Rev. 112 (2012) 724-781.

[45] A. Demessence, D.M. D’Alessandro, M.L. Foo, J.R. Long, J. Am. Chem. Soc. 131 (2009) 8784-8786.

[46] J. An, S.J. Geib, N.L. Rosi, J. Am. Chem. Soc. 132 (2010) 38-39.

[47] J.R.R. Vaidhyanathan, S.S. Iremonger, G.K.H. Shimizu, P.G. Boyd, S. Alavi, T.K. Woo, Science 330 (2010) 650-653.

[48] J.J. Gassensmith, H. Furukawa, R.A. Smaldone, R.S. Forgan, Y.Y. Botros, O.M. Yaghi, J.F. Stoddart, J. Am. Chem. Soc. 133 (2011) 15312-15315.

[49] E. Stavitski, E.A. Pidko, S. Couck, T. Remy, E.J.M. Hensen, Langmuir 27 (2011) 3970-3976.

[50] D. Britt, H. Furukawa, B. Wang, T.G. Glover, O.M. Yaghi, Proc. Natl. Acad. Sci. 106 (2009) 20637-20640.

[51] S. Yang, J. Sun, A.J. Ramirez-Cuesta, S.K. Callear, W.I.F. David, D.P. Anderson, R. Newby, A.J. Blake, J.E. Parker, C.C. Tang, M. Schröder, Nat. Chem. 4 (2012) 887894.

[52] G. Yang, R.G. Raptis, Chem. Commun. (2004) 2058-2059.

[53] G. Yang, P.-C. Duan, K.-G. Shi, R.G. Raptis, Cryst. Growth Des. 12 (2012) $1882-$ 1889.

[54] SMART-NT Software Reference Manual, version 5.059, Bruker AXS, Inc., Madison, WI, 1998

[55] SAINT+ Software Reference Manual, version 5.059, Bruker AXS, Inc., Madison, WI, 1999.

[56] G.M. Sheldrick, SHELXS-90, Program for the Solution of Crystal Structure, University of Gottingen, Gottingen, Germany, 1986.

[57] G.M. Sheldrick, SHELXL-97, Program for the Refinement of Crystal Structure, University of Gottingen, Göttingen, Germany, 1997.

[58] SHELXTL-NT Software Reference Manual, version 5.059, Bruker AXS, Inc., Madison, WI, 1998.

[59] A.L. Spek, PLATON, a Multipurpose Crystallographic Tool, Utrecht University, Utrecht, 2008.

[60] B. Delley, J. Chem. Phys. 92 (1990) 508-517.

[61] B. Delley, J. Chem. Phys. 113 (2000) 7756-7764.

[62] J.P. Pedrew, K. Burke, M. Ernzerhof, Phys. Rev. Lett. 77 (1996) 3865-3868.

[63] Y. Zhang, W. Yang, Phys. Rev. Lett. 80 (1998) 890.

[64] V. Barone, M. Casarin, D. Forrer, M. Pavone, M. Sambi, A. Vittadini, J. Comput. Chem. 30 (2009) 934-939.

[65] P. Giannozzi, S. Baroni, N. Bonini, M. Calandra, R. Car, C. Cavazzoni, D. Ceresoli, G. Chiarotti, M. Cococcioni, I. Dabo, A.D. Corso, S. De Gironcoli, S. Fabris, G. Fratesi, R. Gebauer, U. Gerstmann, C. Gougoussis, A. Kokalj, M. Lazzeri, L. Martin-Samos, N. Marzari, F. Mauri, R. Mazzarello, S. Paolini, A. Pasquarello, L. Paulatto, C. Sbraccia, S. Scandolo, G. Sclauzero, A.P. Seitsonen, A. Smogunov, P. Umari, R.M. Wentzcovitch, J. Phys. Condens. Matter 21 (2009) 395502 (19 pages).

[66] D. Vanderbilt, Phys. Rev. B 41 (1990) 7892-7895. 
[67] J.-P. Zhang, Y.-B. Zhang, J.-B. Lin, X.-M. Chen, Chem. Rev. 112 (2012) $1001-$ 1033.

[68] C. Yang, U. Kaipa, Q.Z. Mather, X. Wang, V. Nesterov, A.F. Venero, M.A. Omary, J. Am. Chem. Soc. 133 (2011) 18094-18097.

[69] D.D. Do, Adsorption Analysis: Equilibria and Kinetics, Imperial College Press, London, 1998.

[70] A. Kapoor, J.A. Ritter, R.T. Yang, Langmuir 5 (1989) 1118-1121.

[71] A. Bondi, J. Phys. Chem. 68 (1964) 441-451.

[72] D.R. Lide, CRC Handbook of Chemistry and Physics, eightyninth ed., CRC Press, New York, 2008 (p. 10-171-10-172).

[73] A.L. Myers, J.M. Prausnitz, AlChE J. 11 (1965) 121-127.

[74] J.M. Simmons, H. Wu, W. Zhou, T. Yildirim, Energy Environ. Sci. 4 (2011) 2177 2185.

[75] H. Furukawa, N. Ko, Y.B. Go, N. Aratani, S.B. Choi, E. Choi, A.O. Yazaydin, R.Q. Snurr, M. O’Keeffe, J. Kim, O.M. Yaghi, Science 329 (2010) 424-428.

[76] Y. Sakata, S. Furukawa, M. Kondo, K. Hirai, N. Horike, Y. Takashima, H. Uehara, N. Louvain, M. Meilikhov, T. Tsuruoka, S. Isoda, W. Kosaka, O. Sakata, S. Kitagawa, Science 339 (2013) 193-196.

[77] S. Horike, S. Shimomura, S. Kitagawa, Nat. Chem. 1 (2009) 695-704.
[78] O.M. Yaghi, M. O’Keeffe, N.W. Ockwig, M. Eddaoudi, J. Kim, Nature 423 (2003) 705-714.

[79] X. Zhao, B. Xiao, A.J. Fletcher, K.M. Thomas, D. Bradshaw, M. Resseinsky, Science 306 (2004) 1012-1015.

[80] C. Yang, X. Wang, M. Omary, Angew. Chem. Int. Ed. 48 (2009) 2500-2505.

[81] A.M. Plonka, D. Banerjee, W.R. Woerner, Z. Zhang, N. Nijem, Y.J. Chabal, J. Li, J.B. Parise, Angew. Chem. Int. Ed. 52 (2013) 1692-1695.

[82] N. Nijem, P. Thissen, Y. Yao, R.C. Longo, K. Roodenko, H. Wu, Y. Zhao, K. Cho, J. Li, D.C. Langreth, Y.J. Chabal, J. Am. Chem. Soc. 133 (2011) 12849-12857.

[83] A. Comotti, S. Bracco, G. Distefano, P. Sozzani, Chem. Commun. (2009) 284286.

[84] C.H. Görbitz, New J. Chem. 27 (2003) 1789-1793.

[85] Y.J. Choi, J.H. Choi, K.M. Choi, J.K. Kang, J. Mater. Chem. 21 (2011) 1073-1078.

[86] R. Yun, J. Duan, J. Bai, Y. Li, Cryst. Growth Des. 13 (2013) 24-26.

[87] T.M. McDonald, D.M. D’Alessandro, R. Krishna, J.R. Long, Chem. Sci. 2 (2011) 2022-2028.

[88] J.A. Mason, K. Sumida, Z.R. Hern, R. Krishna, J.R. Long, Energy Environ. Sci. 4 (2011) 3030-3040. 